\title{
PCR Based Random Mutagenesis Approach for a Defined DNA Sequence Using the Mutagenic Potential of Oxidized Nucleotide Products
}

\author{
Utpal Mohan ${ }^{\#}$, Shubhangi Kaushik ${ }^{\#}$ and Uttam Chand Banerjee*
}

\author{
Biocatalysis and Protein Engineering Group, Department of Pharmaceutical Technology, National Institute of Pharma- \\ ceutical Education and Research, Sector 67, S.A.S. Nagar-160062, Punjab, India
}

\begin{abstract}
Oxidizing conditions have not been explored well for the in vitro random mutagenesis in directed evolution. The mutagenic potential of diverse range of oxidized products is well reported in literature. Incorporation of errors during PCR in the presence of oxidized nucleotides can be a very effective alternative to error prone PCR as the transversion mutation frequency is higher in the former case. Earlier reports used a single purified oxidized nucleotide for introducing mutations during polymerase chain reaction. This could be further improved using the entire range of oxidized nucleotides to widen the mutation spectrum. The highlight of the present work lies in the fact that the oxidized nucleotides used in this study were generated by incubating the mixture of all the four nucleotides (dATP, dCTP, dTTP and dGTP) with an oxidizing agent, ferrous sulphate. This oxidized nucleotide mixture was then directly used without purification in polymerase chain reaction to introduce random mutations. The $100 \mu \mathrm{M}$ oxidized nucleotides mixture treated with $5 \mathrm{mM} \mathrm{FeSO}_{4}$ for 10 minutes along with $200 \mu \mathrm{M}$ nucleotides are the optimized parameters for PCR amplification of a desired gene. The effect of manganese and magnesium ions over the incorporation of oxidized nucleotides was also investigated. An optimized PCR based approach which can be an efficient alternative to error-prone PCR for introducing random mutations in a defined gene sequence has been successfully developed.
\end{abstract}

Keywords: Random mutagenesis, oxidized nucleotides, error prone PCR.

\section{INTRODUCTION}

Oxidative stress has been shown to be involved in biological processes such as mutagenesis, carcinogenesis and ageing [1-3]. Reactive oxygen species (ROS) produced in cells react with DNA and its precursors, and the oxidative DNA lesions formed causes mutational events. One of the oxidative DNA lesions is 8-hydroxydeoxyguanosine $(8-\mathrm{OH}-$ dG; 7,8-dihydro-8- oxodeoxyguanosine) [4-7] and it pairs with $\mathrm{dA}$ as well as $\mathrm{dC}$ in in vitro DNA synthesis and induces mainly $\mathrm{G} \rightarrow \mathrm{T}$ transversions in cells [8-16]. Moreover, 2 hydroxydeoxyadenosine (2- OH-dA) and 5-hydroxydeoxycytidine $(5-\mathrm{OH}-\mathrm{dC})$, which are produced by ROS, are miscoding and mutagenic in nature [17-21]. Major products reported are 2-hydroxydeoxyadenosine (2-OH-dA), 8, 5'-cyclodeoxyadenosine (cyclo-dA), 5-hydroxydeoxycytidine (5$\mathrm{OH}-\mathrm{dC}), 8$-hydroxydeoxyguanosine (8-OH-dG), 5-formyldeoxyuridine (5-CHO-dU) and glyoxal [22]. These results suggested that triphosphates of 2-OH-dA, cyclo-dA, 8-OHdA, cyclo-dG, 5-CHOdU, 5-OH-dC, and glyoxal-dG as well as 8-OH-dG may be produced in cells with different ratio by various types of oxidative stress and involved in mutagenesis and carcinogenesis. Glyoxal is a major product of DNA oxidation in which Fenton-type oxygen free radical-forming systems are involved. It had been reported that the yield of glyoxal was much higher (17-fold) than that of

*Address correspondence to this author at the Biocatalysis and Protein Engineering Group, Department of Pharmaceutical Technology, National Institute of Pharmaceutical Education and Research, Sector 67, S.A.S. Nagar-160062, Punjab, India; Tel: +91 172 2214682-87; Fax: +91 172 2214692; E-mail: ucbanerjee@niper.ac.in

${ }^{\#}$ Equal contribution to the manuscript.
8- hydroxydeoxyguanosine (8-OH-dG). Moreover, the formation of glyoxal was estimated to be 13- fold more than that of 8-OH-dG when mixtures of deoxynucleosides were treated [22]. Glyoxal is known to be mutagenic in Salmonella typhimurium strains TA100, TA102 and TA104 [2325]. It was further reported that glyoxal induces mutations at G:C base pairs, in a study using a set of seven S. typhimurium strains (TA7001-TA7006 and TA98) [26]. Moreover, glyoxal induces mutations mainly at $\mathrm{G}: \mathrm{C}$ base pairs in wild-type Escherichia coli [27]. It was found that glyoxal induced predominantly $\mathrm{G}: \mathrm{C} \rightarrow \mathrm{T}: \mathrm{A}$ transversions, followed by $\mathrm{G}: \mathrm{C} \rightarrow \mathrm{C}: \mathrm{G}, \mathrm{A}: \mathrm{T} \rightarrow \mathrm{T}: \mathrm{A}$ and $\mathrm{G}: \mathrm{C} \rightarrow \mathrm{A}: \mathrm{T}$ mutations. Oxidation of the methyl group of thymine produced 5hydroxymethyl uracil $(5-\mathrm{hmU})$ and as major products. One of the attractive approaches for random mutagenesis is the addition of a mutagenic nucleotide analog during PCR, to enhance the mutation frequency. 6-(2-Deoxy $\beta-D-$ ribofuranosyl)-3,4-dihydro-8H-pyrimido-[4,5-C][1,2] oxazin7-one-5-triphosphate (dPTP) and 8-oxo-2'-deoxyguanosine triphosphate (8-oxodGTP) were previously used to create mutations. The former induces $\mathrm{A}: \mathrm{T} \rightarrow \mathrm{G}: \mathrm{C}$ and $\mathrm{G}: \mathrm{C} \rightarrow \mathrm{A}: \mathrm{T}$ transitions, and the latter elicits $\mathrm{A}: \mathrm{T} \rightarrow \mathrm{C}: \mathrm{G}$ transversions [28]. The 2-hydroxyadenine base in DNA induces A:T $\rightarrow \mathrm{G}: \mathrm{C}$ and $\mathrm{A}: \mathrm{T} \rightarrow \mathrm{C}: \mathrm{G}$ mutations in living cells and 2-OH-dATP has the potential to elicit $\mathrm{G}: \mathrm{C} \rightarrow \mathrm{A}: \mathrm{T}$ and $\mathrm{G}: \mathrm{C} \rightarrow \mathrm{T}: \mathrm{A}$ mutations [29]. It was reported that a 2- substituted purine nucleotide analog, 2-hydroxy-2-deoxyadenosine 5-triphosphate (2OHdATP), was used for the random PCR mutagenesis [30]. It was also reported by them that PCR with $8-\mathrm{OH}-\mathrm{dGTP}$, after error-prone PCR with $\mathrm{Mn}^{2+}$ induced $\mathrm{A}: \mathrm{T} \rightarrow \mathrm{G}: \mathrm{C}$ and $\mathrm{G}: \mathrm{C} \rightarrow \mathrm{A}: \mathrm{T}$ transitions and $\mathrm{A}: \mathrm{T} \rightarrow \mathrm{T}: \mathrm{A}$ and $\mathrm{A}: \mathrm{T} \rightarrow \mathrm{C}: \mathrm{G}$ transversions with similar frequencies. These results indicated 
that the combination of the $\mathrm{Mn}^{2+}$-PCR and 8-OH-dGTP PCR may be useful to generate random mutant libraries of proteins or functional nucleic acids [31].

It has been very well demonstrated that all these oxidized products have diverse mutagenic capacity. Oxidizing conditions have not been explored well for in vitro random mutagenesis in directed evolution experiments. Herein, we report the development and optimization of a PCR based system where the entire oxidized nucleotide products were used to have a highly efficient random chemical mutagenesis approach. This may be an effective alternative method for the error prone PCR and could be used for inducing wide spectrum of transition and transversion mutations with higher frequencies.

\section{MATERIALS AND METHOD}

\subsection{Random Mutagenesis with Oxidized Nucleotides}

Pseudomonas aeruginosa lipase encoding gene was amplified by the specific forward 5' GCCATATGATGACACACAAGAGGTGTGGCCCGC 3' flanked with NdeI restriction site and reverse oligonucleotides 5' CGGATGTCAGAGGAGATAAATCTGTCAGTAGAC 3' flanked with XhoI restriction site in $1 \mathrm{X}$ Taq buffer with $\mathrm{KCl}, 1.5 \mathrm{mM}$ $\mathrm{MgCl}_{2}, 200 \mu \mathrm{M}$ dNTP, 0.1-0.5 $\mu \mathrm{M}$ primer (forward and reverse), 1-2 units Taq polymerase and $100 \mathrm{ng}$ genomic DNA. DNA molecular weight marker and all the PCR components except primers were from MBI fermentas GMBH, Germany. PCR was done in Eppendorf Master cycler gradient (Eppendorf AG, Germany) under the following conditions: initial denaturation at $94^{\circ} \mathrm{C}$ for $10 \mathrm{~min}$ followed by cycling conditions, denaturation at $94^{\circ} \mathrm{C}$ for $1 \mathrm{~min}$, annealing at $58^{\circ} \mathrm{C}$ for 1 min, elongation at $72^{\circ} \mathrm{C}$ for $1 \mathrm{~min} 30 \mathrm{sec}$ (repeated for 30 cycles). Final extension at $72^{\circ} \mathrm{C}$ for $10 \mathrm{~min}$ was used to complete the reaction. The PCR amplification of lipase encoding gene was done in the presence of oxidized nucleotides (dNTP). dNTP mixture was incubated for various time intervals in the presence of 5-10 $\mathrm{mM} \mathrm{FeSO}_{4}$. Mannitol $(0.5$ M) was used to stop the oxidation reaction. This oxidized nucleotide mixture was added to the normal polymerase chain reaction mixture and the PCR was run. The oxidized nucleotide mixture was used in combination with normal dNTP in the polymerase chain reaction. Except oxidized dNTP, all other components of a normal polymerase chain reaction were added before the incubation of the nucleotides with the oxidizing agent was over. Oxidized dNTP was always the last component added in the reaction mixture in all the experiments. Taq polymerase was added just a minute before the incubation of nucleotides was over. Care was taken to be quick in setting the reaction. All other components were kept same as in any normal polymerase chain reaction. The densitometry analysis was performed using the Quantity one software associated with the gel documentation unit (Biorad, India).

The amplification product obtained under the optimised oxidised condition was purified by gel extraction using a QIAquick PCR purification kit (Qiagen) and ligated to a linear, $\mathrm{pDrive}$ (T-A based) cloning vector (Qiagen). The ligation mixture was then transformed to E.coli DH5 $\alpha$ cells. The sequencing of the mutants was performed at Bangalore Genie, India.

\subsection{Effect of Concentration of Oxidizing Agent}

To observe the effect of concentration of oxidizing agent, dNTP were incubated with various concentrations of oxidizing agent $\left(\mathrm{FeSO}_{4}\right)$ for 10 minutes at $37^{\circ} \mathrm{C}$. All other components were kept same as in any normal polymerase chain reaction.

\subsection{Effect of Incubation Time with Oxidizing Agent $\left(\mathrm{FeSO}_{4}\right)$}

To observe the effect of incubation time with the oxidizing agent, dNTP was added with the oxidizing agent and incubated for various time intervals. This oxidized dNTP mixture was then added to the polymerase chain reaction mixture.

\subsection{Effect of Manganese Ions on PCR Fidelity}

Manganese $(500 \mu \mathrm{M})$ in a normal polymerase chain reaction results in the incorporation of errors. The effect of manganese in the incorporation of oxidized nucleotides was checked during polymerase chain reaction. It was checked by adding $500 \mu \mathrm{M} \mathrm{MnCl}_{2}$ to the polymerase chain reaction mixture in the presence and absence of oxidized nucleotides.

\subsection{Effect of Oxidized Nucleotide Concentration on Taq Polymerase Activity}

To observe the effect of oxidized nucleotide concentration, they were added to the polymerase chain reaction mixture in varying concentrations. All other components were kept same as in any normal polymerase chain reaction.

\subsection{Effect of Concentration of Nucleotides and $\mathrm{MgCl}_{2}$} over the Incorporation of Oxidized Nucleotides

To observe the effect of untreated dNTPs and $\mathrm{MgCl}_{2}$, untreated dNTP was varied with and without $\mathrm{MgCl}_{2}$ in the reaction mixture.

\subsection{Effect of $\mathrm{MgCl}_{2}$ over the Incorporation of Oxidized Nucleotides}

Increase in $\mathrm{MgCl}_{2}$ concentration in the polymerase chain reaction results in the decreased fidelity of Taq polymerase. This allows misincorporation of nucleotides in the growing DNA template in the polymerase chain reaction. To observe the effect of $\mathrm{MgCl}_{2}$ over the incorporation of oxidized nucleotides, $7.5 \mathrm{mM} \mathrm{MgCl} 2$ was added in the polymerase reaction mixture in the presence of 50 and $100 \mu \mathrm{M}$ oxidized nucleotides keeping all the other components constant.

\section{RESULTS AND DISCUSSION}

\subsection{Effect of Concentration of Oxidizing Agent}

Treatment of nucleotides with an oxidizing agent in in vitro condition and using the oxidized nucleotides for random mutagenesis is an approach which is very less explored till now. Unlike to the earlier reports which involved the use of single purified oxidised nucleotide for introducing the errors in defined DNA sequence, the present work employed the use of non-purified oxidised nucleotide mixture for incorporation of the mutations $[30,31]$. Instead of using the oxidizing agent in the PCR reaction mixture, we oxidized the nucleotide mixture by incubating it with $\mathrm{FeSO}_{4}$ (Fig. 1a). The polymerase chain reaction mixture containing all the components in optimized concentration resulted in an intense 
933 bp band. This PCR reaction mixture when supplemented with only the oxidized nucleotides without any untreated dNTPs, resulted in no amplification of lipase encoding gene. Treated dNTP mixture when supplemented with untreated dNTPs, resulted in the appearance of a $933 \mathrm{bp}$ band. It was observed that when the dNTPs were treated with increasing concentration of $\mathrm{FeSO}_{4}$, the PCR yield was decreased. Kamiya et al. used the $5 \mathrm{mM} \mathrm{FeSO}_{4}$ concentration for their studies with single nucleotide oxidation [22]. In the present work, sizeable band intensity was obtained with $5 \mathrm{mM}$ $\mathrm{FeSO}_{4}$ while amplification was negligible with $10 \mathrm{mM}$ $\mathrm{FeSO}_{4}$. Densitometry analysis was also performed to compare the relative PCR product yield (Fig. 1b). The probable explanation behind such an observation may be the increase in the concentration of oxidized nucleotide products which resulted due to the higher concentration of oxidizing agent. This higher concentration of oxidized nucleotide products seems to stall the Taq polymerase enzyme for which oxidized nucleotides products are not the natural substrates.

\subsection{Effect of Incubation Time with Oxidizing Agent $\left(\mathrm{FeSO}_{4}\right)$}

The effect of increasing concentration of oxidizing agent led us next to investigate the role of incubation time with oxidizing agent (Fig. 2). Increasing of incubation time from 10 to 20 minutes led to no amplification of $933 \mathrm{bp}$ lipase gene. This observation indicated the difficulty faced by $\mathrm{Taq}$ polymerase in incorporating oxidized nucleotides to the template. The increased time of incubation had a direct proportionality with the number of oxidized nucleotides in the solution. The effects observed with the increased incubation time might be due to the number of oxidized nucleotides in the solution, oxidation state of the nucleotides and type or chemical nature of the oxidized nucleotides. Since Taq polymerase doesn't have a natural affinity towards oxidized nucleotides, the enzymes seems to be stalled when faced with a high concentration of oxidized nucleotides. This observation suggested that to induce mutation with oxidized nucleotides, the ideal incubation time should be the one at which the concentration of the oxidized nucleotide does not inhibit the polymerizing activity completely. The incubation time was not increased further beyond 20 minutes due to the disappearance of desired band on increasing the incubation time.

\subsection{Effect of Manganese Ion on the PCR Fidelity}

Introduction of manganese in the polymerase chain reaction mixture is one of the mostly used approaches in introducing mutations in a desired DNA sequence. Earlier reports establishing the role of manganese in decreasing the fidelity of Taq polymerase led us to investigate the cooperative role of manganese ion in inducing mutations in case of oxidized nucleotides. Mutagenic PCR involving the combination of the $\mathrm{Mn}^{2+}$-PCR and 8-OH-dGTP PCR has been exploited for inducing the various mutations [31]. In the present work, introduction of manganese in the presence of oxidized dNTPs did not result in any PCR amplification of the desired gene (Fig. 3). Though presence of manganese ions decreased the fidelity of $T a q$ polymerase, the incorporation of oxidized nucleotides was not visible when these two conditions were included in a normal polymerase chain reaction mixture. The probable reason behind such an observation might be the stalling of Taq polymerase in the presence of excess of oxidized nucleotides.

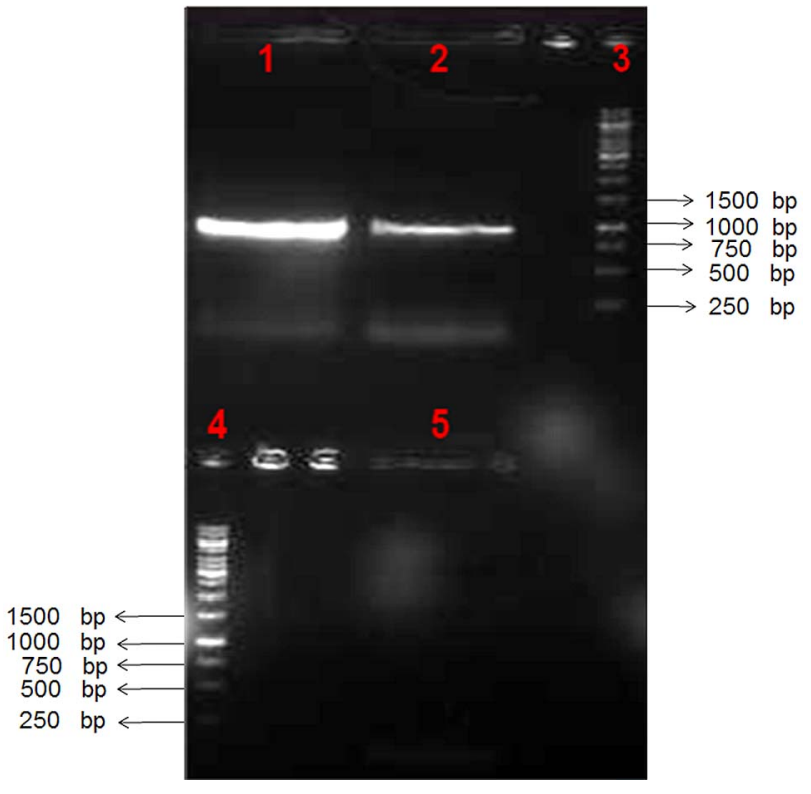

a

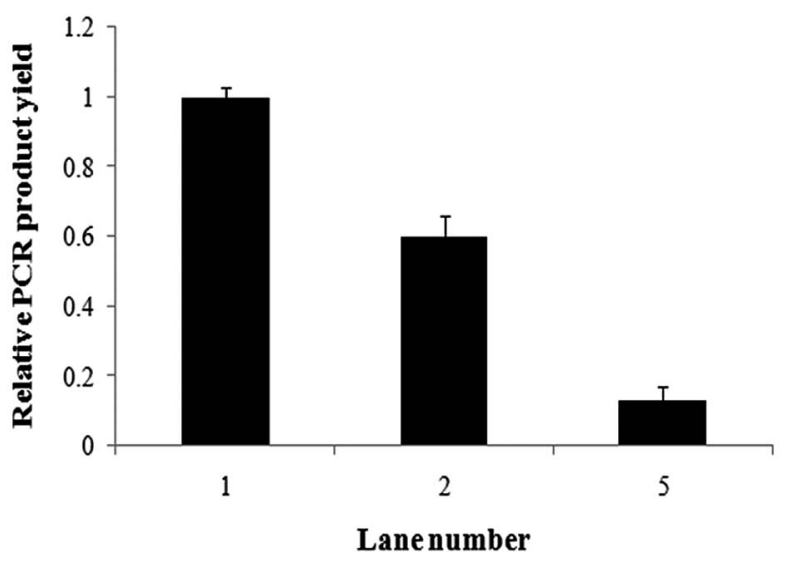

b

Fig. (1). a. Effect of concentration of oxidizing agent on the amplification. The lipase encoding gene was amplified in the presence of different mixtures of nucleotides treated for either 10 minutes or not: $200 \mu \mathrm{M}$ nucleotides (lane 1); $100 \mu \mathrm{M}$ of $5 \mathrm{mM}^{\text {FeSO }}$ treated-nucleotides $+^{-}$ $200 \mu \mathrm{M}$ nucleotides (lane 2); $100 \mu \mathrm{M}$ of $10 \mathrm{mM} \mathrm{FeSO}_{4}$ treated-nucleotides $+200 \mu \mathrm{M}$ nucleotides (lane 5) and visualized by agarose gel electrophoresis and ethidium bromide staining. DNA molecular weight markers are given in lanes 3 and 4.

b. Densitometry analysis to compare the relative PCR product yield. The intensity of the control reaction was designated as 1 (Lane 1 ) and relative intensity of other lanes were quantified against the control reaction. 


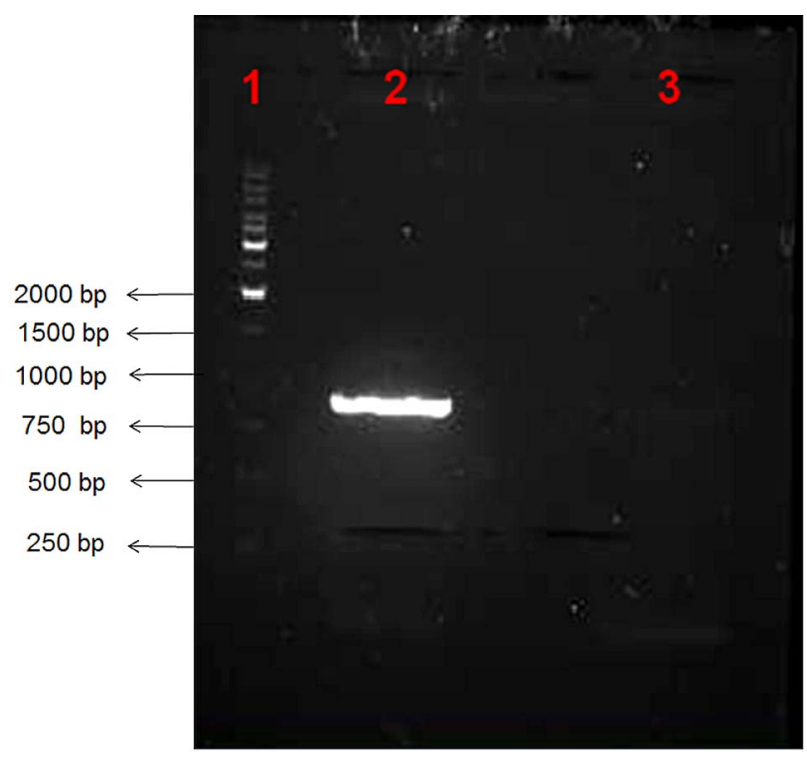

Fig. (2). Effect of incubation time with oxidizing agent on the amplification of the gene of interest. $100 \mu \mathrm{M}$ nucleotides treated with $5 \mathrm{mM} \mathrm{FeSO}_{4}$ for 10 minutes $+200 \mu \mathrm{M}$ nucleotides (lane 2); 100 $\mu \mathrm{M}$ nucleotides treated with $5 \mathrm{mM} \mathrm{FeSO}_{4}$ for 20 minutes $+200 \mu \mathrm{M}$ nucleotides (lane 3). DNA molecular weight marker is shown in lane 1.

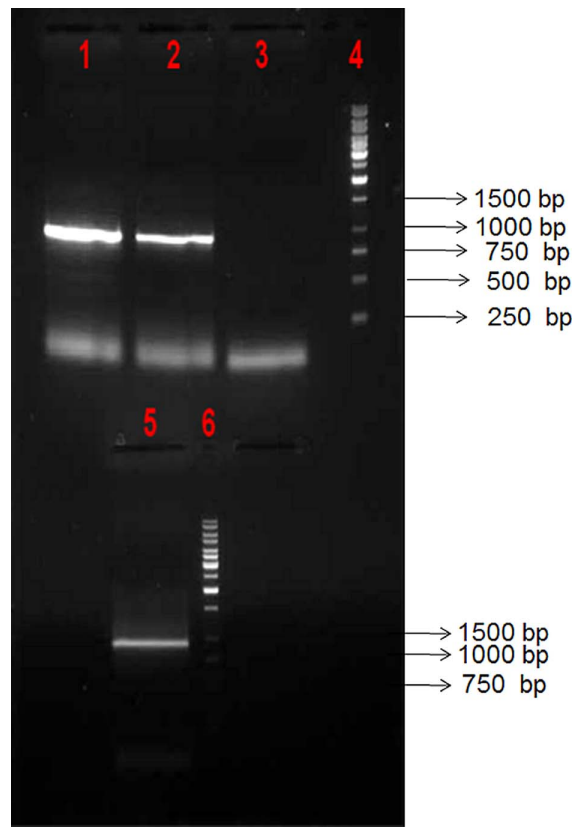

Fig. (3). Effect of manganese ions on the amplification of the gene of interest in the presence of oxidized nucleotide products. $200 \mu \mathrm{M}$ nucleotides (lane 1); $100 \mu \mathrm{M}$ nucleotides treated with $5 \mathrm{mM} \mathrm{FeSO}_{4}$ for 10 minutes $+200 \mu \mathrm{M}$ nucleotides (lane 2); $100 \mu \mathrm{M}$ nucleotides treated with $5 \mathrm{mM} \mathrm{FeSO}_{4}$ for 10 minutes $+200 \mu \mathrm{M}$ nucleotides + $500 \mu \mathrm{M} \mathrm{MnCl}_{2}$ (lane 3); $200 \mu \mathrm{M}$ nucleotides $+500 \mathrm{mM} \mathrm{\textrm {MnCl } _ { 2 }}$ (lane 5). DNA molecular weight marker is shown in lane 4 and 6.

\subsection{Effect of Treated Nucleotide Concentration on Taq Polymerase Activity}

It was clear from the previous experiment that concentration of oxidizing agent affected PCR yield. Further, the ef- fect of varying treated nucleotide concentration (keeping the untreated dNTP concentration constant) was checked (Fig. 4a). It was observed that the treated dNTP concentration when decreased from 100 to $50 \mu \mathrm{M}$ resulted in nearly the same PCR yield while the increased dNTP concentration $(200 \mu \mathrm{M})$ resulted in no amplification of lipase encoding gene. The relative PCR product yield was also quantified for individual lane by densitometry (Fig. 4b). From the above observation it could be concluded that the concentration of treated dNTPs in the reaction mixture is a crucial factor in polymerase chain reaction in the presence of oxidized nucleotides. The amount of oxidized nucleotides in the reaction mixture may or may not affect the Taq polymerase fidelity depending on whether the amount present in the reaction is enough to induce mutations or to stall the Taq polymerase. The excess of oxidized nucleotides in the reaction mixture leads to complete inhibition of Taq polymerase activity as the oxidized nucleotides are not the natural substrates of Taq polymerase. So, a critical concentration of oxidized nucleotides in the reaction mixture is required for polymerase chain reaction in the presence of oxidized nucleotides.

\subsection{Effect of Untreated dNTPs Concentration over the Incorporation of Oxidized Nucleotides}

The importance of a critical concentration of oxidized nucleotides in the reaction mixture led us to investigate the role of concentration of untreated nucleotides in the polymerase chain reaction mixture (Fig. 5). It was observed that amplification was being done by $\mathrm{Taq}$ polymerase when 100 $\mu \mathrm{M}$ treated nucleotides were added with $200 \mu \mathrm{M}$ untreated nucleotides. On decreasing the concentration of untreated nucleotides to $100 \mu \mathrm{M}$ keeping the concentration of treated nucleotides at $100 \mu \mathrm{M}$ (constant), it was observed that there was no amplification of the desired gene. This observation indicated that a proper ratio of oxidized as well as normal dNTP was required for amplification to take place. In such amplification, there were chances for oxidized dNTPs to get incorporated in the desired gene, which in further amplification cycles base pairs with normal bases and thus resulted in introduction of point mutations at random places. It is well established that increased concentration of $\mathrm{MgCl}_{2}$ leads to the decreased substrate specificity of Taq polymerase. In order to investigate the effect of decreased substrate specificity of Taq polymerase on the incorporation of oxidized nucleotides, $7.5 \mathrm{mM} \mathrm{MgCl}_{2}$ was added to the above two reaction mixture. It was found that increased concentration of $\mathrm{MgCl}_{2}$ in the reaction mixture resulted in no amplification in both the conditions. Though increased concentration of $\mathrm{MgCl}_{2}$ decreased the fidelity of Taq polymerase, the incorporation of oxidized nucleotides was not visible when these two conditions were included in a normal polymerase chain reaction mixture. The probable reason behind such an observation might be the stalling of $T a q$ polymerase in the presence of excess of oxidized nucleotides which resulted due the acceptance of oxidized nucleotides by Taq polymerase in the presence of higher concentration of $\mathrm{MgCl}_{2}$.

\subsection{Effect of $\mathrm{MgCl}_{2}$ over the Incorporation of Oxidized Nucleotides}

The role of $\mathrm{MgCl}_{2}$ on the fidelity of Taq polymerase led us to investigate the effect of $\mathrm{MgCl}_{2}$ over the incorporation of oxidized nucleotides during polymerase chain reaction in 

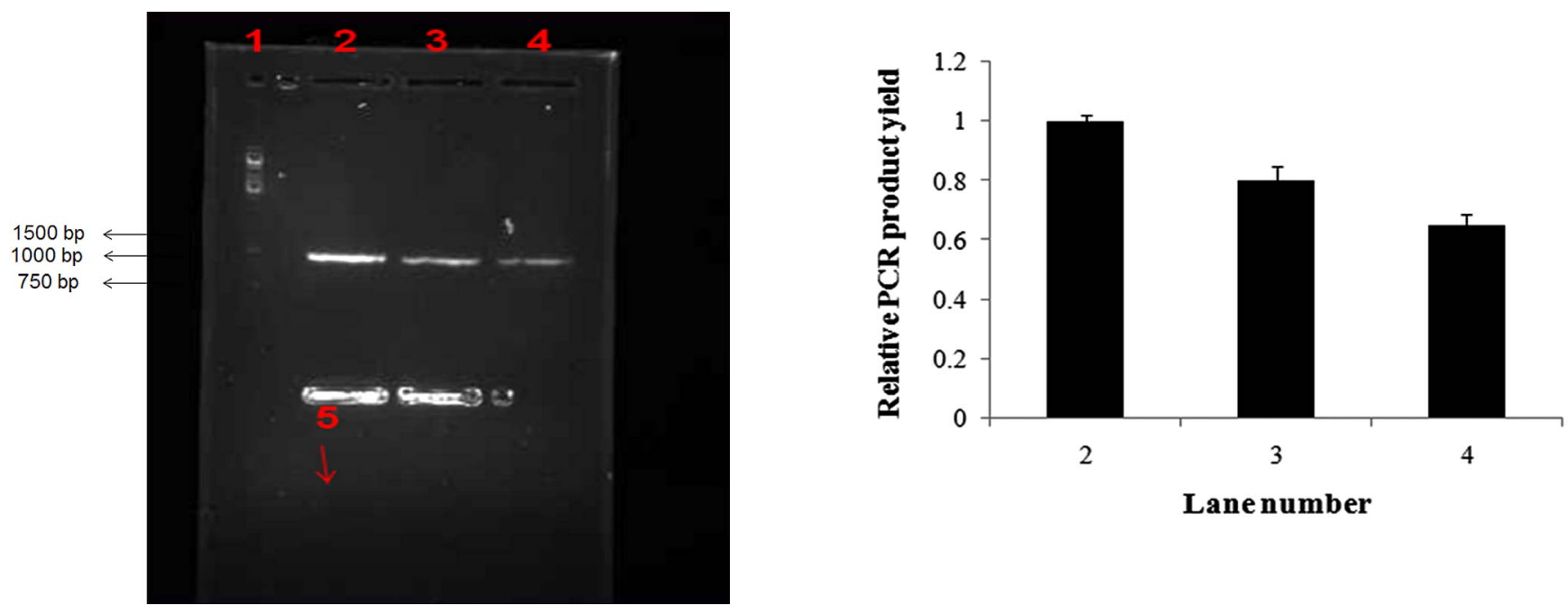

Fig. (4). a. Effect of treated nucleotide concentration on the amplification of the gene of interest. $200 \mu \mathrm{M}$ nucleotides (lane 2 ); $50 \mu \mathrm{M}$ nucleotides treated with $5 \mathrm{mM} \mathrm{FeSO}_{4}$ for 10 minutes $+200 \mu \mathrm{M}$ nucleotides (lane 3); $100 \mu \mathrm{M}$ nucleotides treated with $5 \mathrm{mM} \mathrm{FeSO}_{4}$ for 10 minutes $+200 \mu \mathrm{M}$ nucleotides (lane 4); $200 \mu \mathrm{M}$ nucleotides treated with $5 \mathrm{mM} \mathrm{FeSO}_{4}$ for 10 minutes $+200 \mu \mathrm{M}$ nucleotides (lane 5). DNA molecular weight marker is shown in lane 1.

b. Densitometry analysis to compare the relative PCR product yield. The intensity of the control reaction was designated as 1 (Lane 2 ) and relative intensity of other lanes were quantified against the control reaction.

the presence of oxidized nucleotide mixture (Fig. 6). Reports are available showing the use of increased $\mathrm{MgCl}_{2}$ concentration with oxidised nucleotides for the incorporation of errors in defined DNA sequence [32]. In present case, $\mathrm{MgCl}_{2}$ concentration when increased to $7.5 \mathrm{mM}$ keeping all other components of PCR reaction same, there was a decrease in the band intensity and amplification of non specific fragments took place (Fig. 6, lane 3). The effect of $\mathrm{MgCl}_{2}$ in the presence of oxidized dNTPs was investigated. The significant reduction in amplification of the desired gene was observed when oxidized dNTP $(100 \mu \mathrm{M})$ was supplemented with 7.5 $\mathrm{mM} \mathrm{MgCl}_{2}$ (Fig. 6, lane 6). There was no amplification even when the $\mathrm{MgCl}_{2}$ concentration was decreased to $4.5 \mathrm{mM}$ (Fig. 6, lane 7).

\subsection{Sequencing of Products of PCR Amplification with Oxidized Nucleotides}

All the above results led to the conclusion that $100 \mu \mathrm{M}$ oxidized nucleotides mixture (treated with $5 \mathrm{mM} \mathrm{FeSO}_{4}$ for 10 minutes) along with $200 \mu \mathrm{M}$ nucleotides are the optimized parameters for PCR amplification of a desired gene in the presence of oxidized nucleotide products. The PCRamplified lipase encoding gene obtained using $100 \mu \mathrm{M}$ oxidized nucleotides mixture (treated with $5 \mathrm{mM} \mathrm{FeSO}_{4}$ for 10 minutes) and $200 \mu \mathrm{M}$ nucleotides were cloned and sequenced. Both the transition and transversion mutations were observed in the sequenced clones (Table 1). Sequencing of mutants resulted in the similar pattern of mutations that was earlier reported by Kamiya et al. [30, 31].

\section{CONCLUSIONS}

The entire studies on the oxidized nucleotides led us to conclude that to incorporate errors with oxidized dNTPs; it was necessary to adjust the ratio of the treated and untreated
dNTPs in the reaction mixture, concentration of oxidizing agent and the time of incubation. The polymerizing activity of Taq polymerase was observed to be affected in the presence of an excess oxidized nucleotides. It stalls when the

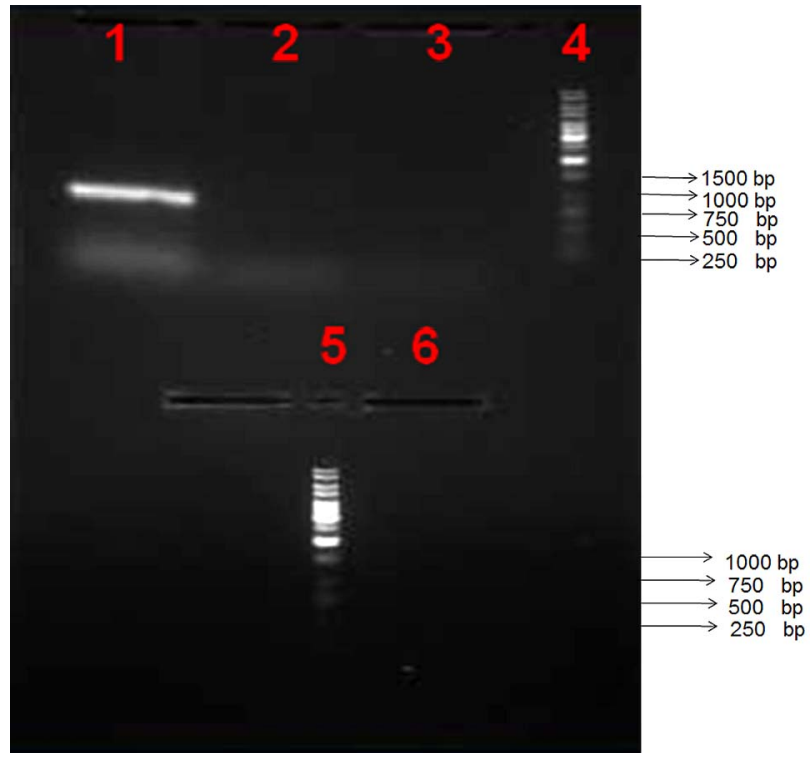

Fig. (5). Effect of untreated dNTPs concentration on the amplification of the gene of interest in the presence of oxidized nucleotide products. $100 \mu \mathrm{M}$ nucleotides treated with $5 \mathrm{mM} \mathrm{FeSO}_{4}$ for 10 minutes $+200 \mu \mathrm{M}$ nucleotides (lane 1 ); $100 \mu \mathrm{M}$ nucleotides treated with $5 \mathrm{mM} \mathrm{FeSO}_{4}$ for 10 minutes $+100 \mu \mathrm{M}$ nucleotides (lane 2); $100 \mu \mathrm{M}$ nucleotides treated with $5 \mathrm{mM} \mathrm{FeSO}_{4}$ for 10 minutes +200 $\mu \mathrm{M}$ nucleotides $+7.5 \mathrm{mM} \mathrm{MgCl}_{2}$ (lane 3); $100 \mu \mathrm{M}$ nucleotides treated with $5 \mathrm{mM} \mathrm{FeSO}_{4}$ for 10 minutes $+100 \mu \mathrm{M}$ nucleotides + $7.5 \mathrm{mM} \mathrm{MgCl}_{2}$ (lane 6). DNA molecular weight marker is shown in lane 4 and 5 . 


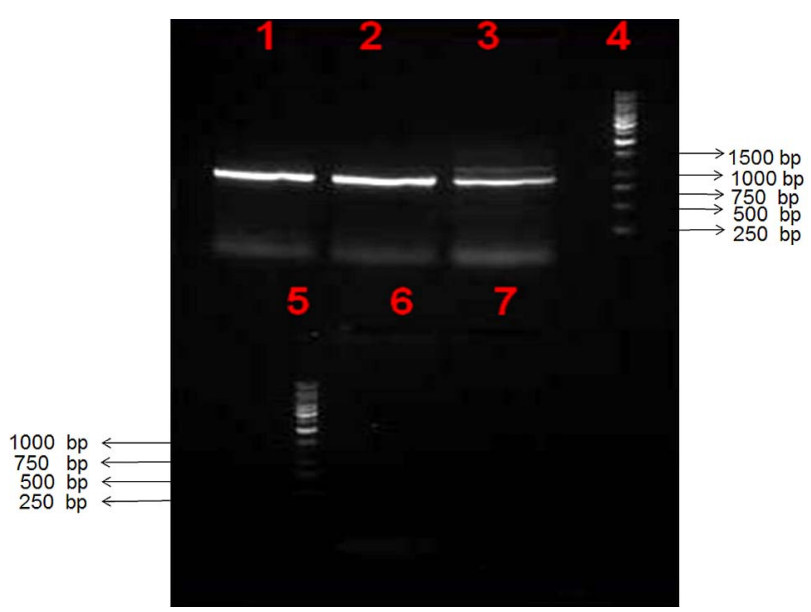

Fig. (6). Effect of $\mathrm{MgCl}_{2}$ on the amplification of the gene of interest in the presence of oxidized nucleotide products. $100 \mu \mathrm{M}$ nucleotides treated with $5 \mathrm{mM} \mathrm{FeSO}_{4}$ for 10 minutes $+200 \mu \mathrm{M}$ nucleotides (lane1); $50 \mu \mathrm{M}$ nucleotides treated with $5 \mathrm{mM} \mathrm{FeSO}_{4}$ for 10 minutes $+200 \mu \mathrm{M}$ nucleotides (lane 2); $200 \mu \mathrm{M}$ nucleotides +7.5 $\mathrm{mM} \mathrm{MgCl} 2$ (lane 3); $50 \mu \mathrm{M}$ nucleotides treated with $5 \mathrm{mM} \mathrm{FeSO}_{4}$ for 10 minutes $+200 \mu \mathrm{M}$ nucleotides $+7.5 \mathrm{mM} \mathrm{MgCl}_{2}$ (lane 6); 50 $\mu \mathrm{M}$ nucleotides treated with $5 \mathrm{mM} \mathrm{FeSO}_{4}$ for 10 minutes $+200 \mu \mathrm{M}$ nucleotides $+4.5 \mathrm{mM} \mathrm{MgCl} 2$ (lane 7). DNA molecular weight marker is shown in lane 4 and 5.

Table 1. Point Mutations in the Variant Generated by PCR in the Presence of Oxidized Nucleotides

\begin{tabular}{|c|c|c|c|}
\hline $\begin{array}{c}\text { Base Pair } \\
\text { Change }\end{array}$ & $\begin{array}{c}\text { Nucleotide } \\
\text { Position }\end{array}$ & $\begin{array}{c}\text { Base Pair } \\
\text { Change }\end{array}$ & $\begin{array}{c}\text { Nucleotide } \\
\text { Position }\end{array}$ \\
\hline \hline $\mathrm{C} \rightarrow \mathrm{T}$ & 210 & $\mathrm{C} \rightarrow \mathrm{T}$ & 303 \\
$\mathrm{~A} \rightarrow \mathrm{G}$ & 245 & $\mathrm{~A} \rightarrow \mathrm{T}$ & 419 \\
$\mathrm{G} \rightarrow \mathrm{C}$ & 259 & $\mathrm{~A} \rightarrow \mathrm{G}$ & 441 \\
$\mathrm{C} \rightarrow \mathrm{T}$ & 280 & $\mathrm{~A} \rightarrow \mathrm{G}$ & 500 \\
\hline
\end{tabular}

number of unnatural nucleotides crosses a critical concentration. Earlier reports used a single pure oxidized nucleotide for introducing mutations [30, 31] during polymerase chain reaction. This was a serious drawback as one requires tedious purification of oxidized nucleotide product before using it in the PCR reaction to induce point mutations. Moreover, the diverse range of oxidized nucleotide products in a single polymerase chain reaction has never been utilized to induce the random mutations. The highlight of the present work lies in the fact that the oxidized nucleotides used in this study were generated by incubating the mixture of all the four nucleotides (dATP, dCTP, dTTP and dGTP) with an oxidizing agent. This oxidized mixture was then used in polymerase chain reaction to introduce random mutations. The diverse range of oxidized products of these four dNTPs (which can induce a wide spectrum of mutations: both transitions and transversions) $[10,17,21,26,29,30,31]$ when used together in a polymerase chain reaction could constitute an efficient alternative to error-prone PCR for introducing random mutations in a defined gene sequence.

\section{ACKNOWLEDGEMENTS}

UM acknowledges NIPER for the senior research fellowship to carry out this study. SK acknowledges DBT for the senior research fellowship to carry out this study.

\section{REFERENCES}

[1] Harman D. The ageing process. Proc Natl Acad Sci USA 1981; 78 : 7124-8.

[2] Ames BN. Dietary carcinogens and anticarcinogens. Science 1983; 221: 1256-64.

[3] Ozawa T. Mechanism of somatic mitochondrial DNA mutations associated with age and diseases. Biochim Biophys Acta 1995; 1271: 177-89.

[4] Kasai H, Tanooka H, Nishimura S. Formation of 8-hydroxyguanine residues in DNA by X-irradiation. Jpn J Cancer Res 1984; 75: 1037-9.

[5] Kasai H, Nishimura S. Hydroxylation of deoxyguanosine at the C-8 position by ascorbic acid and other reducing agents. Nucleic Acids Res 1984; 12: 2137-45.

[6] Dizdaroglu M. Formation of an 8-hydroxyguanine moiety in deoxyribonucleic acid on $\gamma$-, irradiation in aqueous solution. Biochemistry $1985 ; 24$ : 4476-81.

[7] Ohshima H, Iida Y, Matsuda A, Kuwabara M. Damage induced by hydroxyl radicals generated in the hydration layer of gammairradiated frozen aqueous solution of DNA. J Radiat Res 1996; 37: 199-207.

[8] Wood ML, Dizdaroglu M, Gajewski E, Essigmann JM. Mechanistic studies of ionizing radiation and oxidative mutagenesis: genetic effects of a single 8-hydroxyguanine (7-hydro-8-oxoguanine) residue inserted at a unique site in a viral genome. Biochemistry 1990; 29: 7024-32.

[9] Shibutani S, Takeshita M, Grollman AP. DNA synthesis past the oxidation-damaged base 8-oxodG. Nature 1991; 349: 431-4.

[10] Cheng, KC, Cahill DS, Kasai H, Nishimura S, Loeb LA. 8hydroxyguanine, an abundant form of oxidative DNA damage, causes $\mathrm{G} \rightarrow \mathrm{T}$ and $\mathrm{A} \rightarrow \mathrm{C}$ substitutions. J Biol Chem 1992; 267: 166-72.

[11] Kamiya H, Sakaguchi T, Murata N, et al. In vitro replication study of modified bases in ras sequences. Chem Pharm Bull 1992; 40: 2792-5.

[12] Kamiya H, Miura K, Ishikawa H, Inoue H, Nishimura S, Ohtsuka, E. c-Ha-ras containing 8-hydroxyguanine at codon 12 induces point mutations at the modified and adjacent positions. Cancer Res 1992; 52: 3483-5.

[13] Moriya M. Single-stranded shuttle phagemid for mutagenesis studies in mammalian cells, 8-oxoguanine in DNA induces targeted $\mathrm{G} \cdot$ $\mathrm{C} \rightarrow \mathrm{T} \cdot \mathrm{A}$ transversions in simian kidney cells. Proc Natl Acad Sci USA 1993; 90: 1122-6.

[14] Kamiya H, Kamiya MN, Fujimuro M, et al. Comparison of incorporation and extension of nucleotides in vitro opposite 8hydroxyguanine (7,8-dihydro-8-oxoguanine) in hot spots of the cHa-ras gene. Jpn J Cancer Res 1995; 86: 270-6.

[15] Kamiya H, Kamiya MN, Koizume S, Inoue H, Nishimura S, Ohtsuka E. 8- hydroxyguanine (7,8-dihydro-8-oxoguanine) in hot spots of the c-Ha-ras gene. Carcinogenesis 1995; 16: 883-9.

[16] Takimoto K, Tachibana A, Ayaki H, Yamamoto K. Spectrum of spontaneous mutations in the cyclic AMP receptor protein gene on chromosomal DNA of Escherichia coli. J Radiat Res 1997; 38: 2736.

[17] Purmal AA, Kow YW, Wallace SS. Major oxidative products of cytosine, 5- hydroxycytosine and 5-hydroxyuracil, exhibit sequence context-dependent mispairing in vitro. Nucleic Acids Res 1994; 22: $72-8$.

[18] Feig DI, Sowers LC, Loeb LA. Reverse chemical mutagenesis: identification of the mutagenic lesions resulting from reactive oxygen species-mediated damage to DNA. Proc Natl Acad Sci USA 1994; 91: 6609-13.

[19] Kamiya H, Ueda T, Ohgi T, Matsukage A, Kasai H. Misincorporation of dAMP opposite 2-hydroxyadenine, an oxidative form of adenine. Nucleic Acids Res 1995; 23: 761- 6.

[20] Kamiya H, Kasai H. Effects of sequence contexts on misincorporation of nucleotides opposite 2-hydroxyadenine. FEBS Lett 1996; 391: 113-6. 
[21] Kamiya H, Kasai H. Substitution and deletion mutations induced by 2-hydroxyadenine in Escherichia coli, effects of sequence contexts in leading and lagging strands. Nucleic Acids Res 1997; 25: 304-11.

[22] Kamiya MN, Kamiya H, Muraoka M, Kaji H, Kasai H. Comparison of oxidation products from DNA components by $\gamma$-irradiation and Fenton-type reactions. J Radiat Res 1997; 38: 121-31.

[23] Bjeldanes LF, Chew H. Mutagenicity of 1, 1-dicarbonyl compounds: maltol, kojic acid, diacetyl and related substances. Mutat Res 1979; 67: 367-71.

[24] Sayato Y, Nakamuro K, Ueno H. Mutagenicity of products formed by ozonation of naphthoresorcinol in aqueous solutions. Mutat Res 1987; 189: 217-22.

[25] Dorado L, Montoya MR, Mellado JMR. A contribution to the study of the structure mutagenicity relationship for alpha-dicarbonyl compounds using the Ames test. Mutat Res 1992; 269: 301-6.

[26] Kamiya MN, Kaji H, Kasai H. Types of mutations induced by glyoxal, a major oxidative DNA-damage product, in Salmonella typhimurium. Mutat Res 1997; 377: 13-16.
[27] Kamiya MN, Kamiya H, Kaji H, Kasai H. Mutational specificity of glyoxal, a product of DNA oxidation, in the lacI gene of wild-type Escherichia coli W3110. Mutat Res 1997; 377: 255-62.

[28] Zaccolo M, Williams DM, Brown DM, Gheradi E. An approach to random mutagenesis of DNA using mixtures of triphosphate derivatives of nucleoside analogues. J Mol Biol 1996; 255: 589-603.

[29] Kamiya H, Kasai H. Mutations induced by 2-hydroxyadenine on a shuttle vector during leading and lagging strand synthesis in mammalian cells. Biochemistry 1997; 36: 11125-30.

[30] Kamiya H, Ito M, Harashima H. Induction of transition and transversion mutations during random mutagenesis PCR by the addition of 2-hydroxy-dATP. Biol Pharm Bull 2004; 27: 621-3.

[31] Kamiya $\mathrm{H}$, Ito $\mathrm{M}$, Harashima $\mathrm{H}$. Induction of various mutations during PCRs with manganese and 8-hydroxy-GTP. Biol Pharm Bull 2007; 30: 842-4.

[32] Purmal AA, Kow YW, Wallace SS. 5-hydroxypyrimidine deoxynucleoside triphosphates are more efficiently incorporated into DNA by exonuclease free Klenow fragment than 8-oxopurine deoxynucleoside triphosphates. Nucleic Acids Res 1994; 22: 3930-5.

(C) Mohan et al.; Licensee Bentham Open.

This is an open access article licensed under the terms of the Creative Commons Attribution Non-Commercial License (http://creativecommons.org/licenses/by-nc/3.0/) which permits unrestricted, non-commercial use, distribution and reproduction in any medium, provided the work is properly cited. 